\title{
Efeitos da Temperatura e do Tipo de Iniciador na Redução do Teor de Monômero Residual Durante Reações de Copolimerização em Emulsão
}

\author{
Wilson H. Hirota, Marlon M. Reis, Claudia Sayer, Reinaldo Giudici \\ Departamento de Engenharia Química, Escola Politécnica, USP \\ Pedro H. H. Araújo \\ Departamento de Engenharia Química e Engenharia de Alimentos, CTC, UFSC
}

\begin{abstract}
Resumo: Reduzir o teor de monômero residual é uma preocupação de qualquer produtor de polímeros, pois produtos sem, ou com teores muito baixos de monômero residual, apresentam um apelo comercial diferenciado. Neste trabalho são apresentadas e testadas experimentalmente diversas estratégias para reduzir o teor de monômero residual de copolímeros estireno/acrilato de butila produzidos em reações semicontínuas de polimerização em emulsão, que são amplamente utilizados nas indústrias de papel e tintas. Estas estratégias envolvem a adição contínua de iniciador e/ou o aumento da temperatura do reator durante a última etapa da reação, além da adição de um agente redutor e/ou de um iniciador solúvel na fase orgânica. Verificou-se que a combinação adequada de diferentes técnicas pode levar a uma redução significativa no teor residual de monômeros no látex.
\end{abstract}

Palavras-chave: Teor de monômero residual, emulsão, pós-polimerização, estireno, acrilato de butila

\section{Effects of Temperature and Type of Initiators on the Reduction of Residual Monomer Content in Emulsion Copolymerization Reactions}

Abstract: Reducing the residual monomer content is a major concern of every polymer producer, as products with no, or very low levels of residual monomer have a marked commercial appeal. Styrene / butyl acrylate copolymers produced in emulsion polymerization reactions are widely applied in paper and paint industries. In this work, several strategies to reduce the residual monomer content of styrene and butyl acrylate copolymers produced in semicontinuous emulsion polymerization reactions are presented and tested. These strategies involve the continuous addition of initiator, increasing the reaction temperature during the last stage of the reaction, and adding a reducing agent or an initiator that is soluble in the organic phase at this last stage. The adequate combination of some of these techniques may result in a significant reduction of the residual monomer content in the final latex.

Keywords: Residual monomer content, emulsion, postpolymerization, styrene, butyl acrylate.

\section{Introdução}

Os látices poliméricos produzidos em emulsão encontram amplo campo de aplicações industriais, desde adesivos, revestimento de papel, tintas e vernizes, que requerem a formação de filmes contínuos, até sistemas de liberação controlada de medicamentos. O copolímero de estireno e acrilato de butila produzido em emulsão em reatores semicontínuos encontra grande aplicação nas indústrias de papel e de tintas a base de água para aplicação em superfícies externas onde o látex estará sujeito a grandes variações de temperatura, incidência de radiação solar e chuva.

Atualmente, para que uma indústria produtora de látex cresça ou mesmo mantenha a posição no mercado torna-se essencial a melhoria dos processos já existentes e o lançamento de novos produtos. Para o látex final, seja por uma questão de mercado ou de meio ambiente, uma característica que a cada dia se torna mais importante é o baixo teor de monômero residual. Ao apresentar um teor de monômero residual elevado, o látex pode ter um aumento de sua toxicidade, além de apresentar um odor desagradável dos monômeros utilizados para sua produção. Isto dificulta a colocação deste produto no mercado, que a cada dia se torna mais exigente. A redução do monômero residual em látex produzido em emulsão é realizada tradicionalmente por processo de "stripping" [1,2], no qual após a reação de polimerização borbulha-se vapor de água no látex para extrair o monômero residual. Porém, ao reduzir ao máximo o teor de monômero residual ao final da etapa de polimerização, reduz-se a um mínimo o processo posterior de "stripping", minimizando desta forma a quantidade de efluente gerado. Idealmente, se a conversão de monômero

Autor para Correspondência: Reinaldo Giudici, Departamento de Engenharia Química, Escola Politécnica, USP, Caixa Postal 61548, CEP 05424-970, São Paulo, SP. E-mail: rgiudici@usp.br 
em polímero atingir $100 \%$ ao final da reação, o "stripping" poderia ser totalmente dispensado. Ao mesmo tempo, do ponto de vista do produto, uma emulsão com monômero residual zero teria um apelo comercial diferenciado.

Apesar da importância existem poucos trabalhos na literatura tratando da redução do teor de monômero residual e muito menor ainda é o número de trabalhos relacionados com o sistema de polimerização em emulsão de estireno e acrilato de butila $^{[3,4,5]}$.

Anderson e Brouwer ${ }^{[3]}$ compararam o efeito da adição de diferentes iniciadores sobre os teores de monômero residual em diversos copolímeros (estireno/acrilato de butila, acetato de vinila/acrilato de butila/ácido metacrílico e acrilato de butila/metacrilato de metila/ácido metacrílico) produzidos em emulsão. Os autores verificaram que pares de oxi-redução compostos por óxidos ou hidroperóxidos orgânicos, que formam radicais solúveis na fase orgânica onde se encontra o monômero não reagido, são mais eficientes para a redução dos teores de monômero residual do que os iniciadores térmicos solúveis em água (persulfato de potássio). Entretanto é importante destacar que neste estudo utilizaram-se estratégias de pós-polimerização aplicadas durante o armazenamento do polímero, isto é, à temperatura ambiente. Além disso os autores observaram que os polímeros pós-polimerizados com hidroperóxidos orgânicos apresentaram diâmetros médios de partícula maiores e pesos moleculares muito menores do que os polímeros pós-polimerizados com persulfato de potássio.

O objetivo deste trabalho é estudar estratégias para reduzir o teor de monômero residual no copolímero de estireno e acrilato de butila para serem aplicadas diretamente no reator de polimerização após o período de alimentação dos reagentes nas reações semi-contínuas de copolimerização em emulsão.

\section{Experimental}

\section{Reagentes}

Em todas as polimerizações foi utilizada água destilada e deionizada. Os reagentes, de grau industrial, tais como monômeros (estireno, Sty, acrilato de butila, BuA, e ácido acrílico, AA), emulsificante (dodecil sulfato de sódio, SLS) e o agente tamponante $\left(\mathrm{Na}_{2} \mathrm{CO}_{3}\right)$, foram usados como fornecidos, visando representar melhor as condições encontradas na indústria. Como iniciador foram utilizados persulfato de sódio $\left(\mathrm{Na}_{2} \mathrm{~S}_{2} \mathrm{O}_{8}, \mathrm{NaPS}\right)$ e terc-butil-hidroperóxido (TBH) e como agente redutor o metabissulfito de sódio $\left(\mathrm{Na}_{2} \mathrm{~S}_{2} \mathrm{O}_{5}, \mathrm{MBS}\right)$.

\section{Procedimento Experimental}

As reações foram realizadas mediante um processo semicontínuo a $70{ }^{\circ} \mathrm{C}$ na unidade experimental automatizada, apresentada na Figura 1, composta por: reator de 3 litros em aço inox 316, para alta pressão (Büchi Glass) com condensador de refluxo, agitador mecânico (até 500.000 $\mathrm{cP})$, variador de velocidade, camisa de aquecimento, sistema de controle de temperatura, com interface para sistema

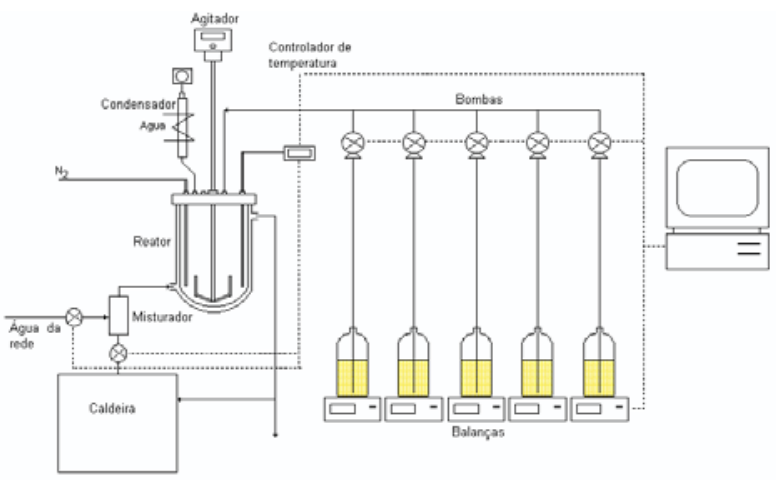

Figura 1. Unidade experimental usada nas reações semi-contínuas de copolimerização de estireno e acrilato de butila em emulsão.

de aquisição de dados; bombas dosadoras (Prominent), balanças (Marte), sistema de aquisição de dados (LabView), placas e acessórios para sistema de aquisição de dados, aquecedor indutivo (COELMA) e termorresistências. A velocidade de agitação foi de 200 rpm e as vazões de alimentação dos monômeros e da fase aquosa foram constantes e ajustadas para se completarem em 90 minutos. A Tabela 1 apresenta a formulação usada nas reações.

$\mathrm{Na}$ formulação foi incluída uma pequena quantidade de ácido acrílico (AA) $(\sim 0,5 \%$ em peso com relação ao monômero total); o uso de pequenas quantidades de monômeros polares é freqüente na fabricação de tintas e vernizes porque aumentam a estabilidade do látex e a sua capacidade de adesão. $\mathrm{O}$ agente tamponante foi adicionado para controlar o $\mathrm{pH}$ do meio reacional e reduzir a hidrólise dos monômeros.

As conversões instantânea e global dos monômeros foram calculadas usando dados gravimétricos, o diâmetro médio das partículas foi medido por difração dinâmica de luz (Coulter N4 Plus) e o número de partículas poliméricas foi calculado a partir dos dados de conversão instantânea e de tamanho médio das partículas. $\mathrm{O}$ teor de monômero no látex foi medido por cromatografia gasosa com "head-space" (HS-GC17A Shimadzu) usando a técnica de evaporação total das amostras para evitar o efeito da matriz ${ }^{[6,7]}$. A composição acumulada do copolímero foi calculada a partir do perfil de

Tabela 1. Formulação base utilizada nas reações. (Tempo de alimentação $=90$ minutos, Teor de sólidos final $=33 \%, \mathrm{~T}=70^{\circ} \mathrm{C}$ e Velocidade de agitação $=$ $200 \mathrm{rpm})$.

\section{Reagente Carga Inicial Alimentação 1 Alimentação 2}

\begin{tabular}{lccc}
\hline Sty $(\mathrm{g})$ & - & 447,12 & - \\
$\mathrm{BuA}(\mathrm{g})$ & - & 447,34 & - \\
$\mathrm{AA}(\mathrm{g})$ & - & 4,44 & - \\
Água $(\mathrm{g})$ & 1700,00 & - & 114,80 \\
$\mathrm{SLS}(\mathrm{g})$ & 9,443 & - & - \\
$\mathrm{Na}_{2} \mathrm{~S}_{2} \mathrm{O}_{8}(\mathrm{~g})$ & - & - & 4,940 \\
$\mathrm{Na}_{2} \mathrm{CO}_{3}(\mathrm{~g})$ & 4,512 & - & - \\
\hline
\end{tabular}

Obs: As taxas de alimentação são constantes. 
Tabela 2. Resumo das estratégias adotadas após o período de alimentação dos reagentes visando a redução dos teores de monômero residual.

\section{Iniciador/Redutor}

\begin{tabular}{ccccc}
\cline { 3 - 5 } Reação & $\begin{array}{c}\text { Temperatura } \\
\left({ }^{\circ} \mathbf{C}\right)\end{array}$ & $\begin{array}{c}\text { NaPS } \\
(\mathbf{g})\end{array}$ & $\begin{array}{c}\text { TBH } \\
(\mathbf{g})\end{array}$ & $\begin{array}{c}\text { MBS } \\
(\mathbf{g})\end{array}$ \\
\hline StyBA1 & & \multicolumn{3}{c}{ Reação base } \\
StyBA2 & $80^{\mathrm{a}}$ & - & - & - \\
StyBA3 & $80^{\mathrm{a}}$ & $3,21^{\mathrm{b}}$ & - & - \\
StyBA4 & - & $3,21^{\mathrm{b}}$ & - & $5,93^{\mathrm{c}}$ \\
StyBA4x & - & $5,82^{\mathrm{d}}$ & - & $1,41^{\mathrm{e}}$ \\
StyBA6 & - & - & $3,18^{\mathrm{f}}$ & $5,93^{\mathrm{c}}$ \\
StyBA7 & $90^{\mathrm{a}}$ & - & $3,52^{\mathrm{f}}$ & $5,93^{\mathrm{c}}$ \\
StyBA8 & $90^{\mathrm{a}}$ & - & - & - \\
\hline
\end{tabular}

NaPS - persulfato de sódio; TBH - terc-butil-hidroperóxido; MBS metabissulfito de sódio.

a mudança de temperatura após período de alimentação com transiente de 3

e 6 minutos, respectivamente, para $80^{\circ} \mathrm{C}$ e $90{ }^{\circ} \mathrm{C}$

b alimentado dissolvido em 76,79 g de água durante 20 minutos

c alimentado dissolvido em $62,39 \mathrm{~g}$ de água durante 60 minutos

d alimentado dissolvido em 139,18 g de água durante 60 minutos

${ }^{e}$ adicionado aos 110 minutos dissolvido em 14,89 g de água

${ }^{\mathrm{f}}$ adicionado aos 110 minutos
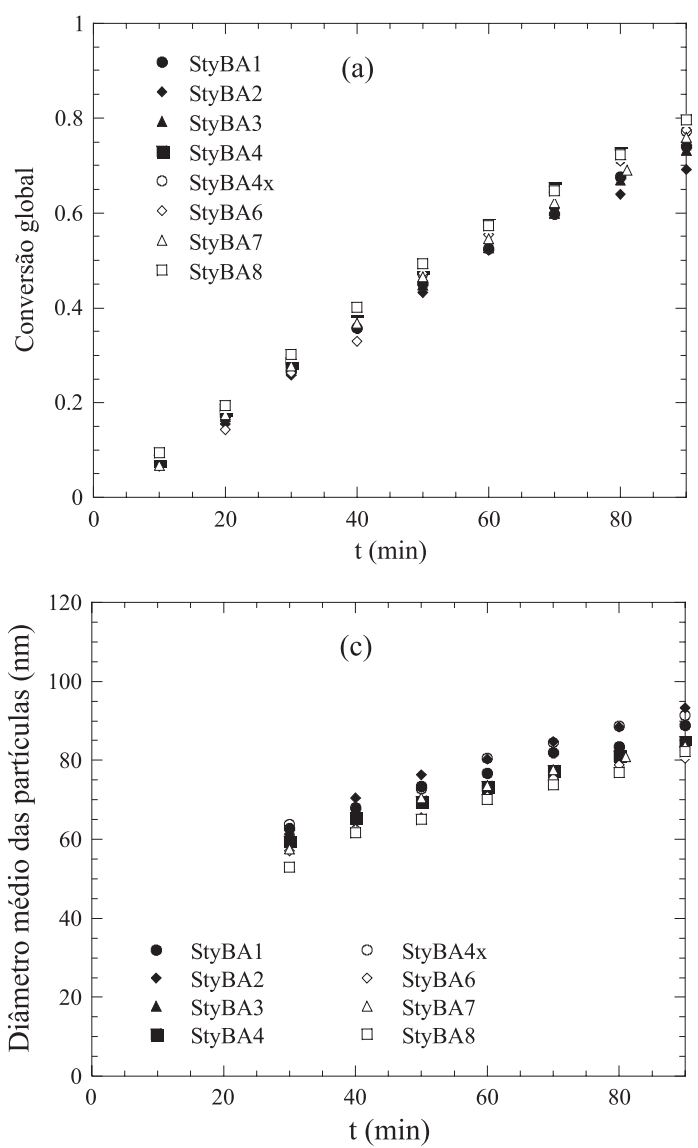

alimentação dos monômeros e dos dados de monômero residual medidos por cromatografia gasosa com "head-space". A acurácia das medidas dos teores de monômero por cromatografia gasosa foi determinada por Leiza e colaboradores $^{[8]}$ através da comparação com a composição medida por ${ }^{1} \mathrm{H}$ RMN.

A Tabela 2 apresenta as diferentes estratégias aplicadas a partir de 90 e/ou 110 minutos de reação (o período de alimentação termina aos 90 minutos de reação) para a redução dos teores de monômero residual. Durante os 90 minutos iniciais todas as reações foram realizadas seguindo a mesma formulação, apresentada na Tabela 1 . Na reação base (StyBA1, StyBA1a e StyBA1b), passado este período de alimentação, o reator foi mantido a $70^{\circ} \mathrm{C}$ por mais 150 minutos, visando o consumo dos monômeros.

\section{Resultados e Discussão}

Na Figura 2 são comparadas as evoluções de variáveis como: conversão global, composição molar acumulada do copolímero, diâmetro médio e número de partículas por massa de meio reacional. Como os monômeros são alimentados com uma vazão lenta e constante a conversão global evolui de forma quase linear em relação ao tempo de reação durante o período de alimentação (Figura 2a) e a composição do
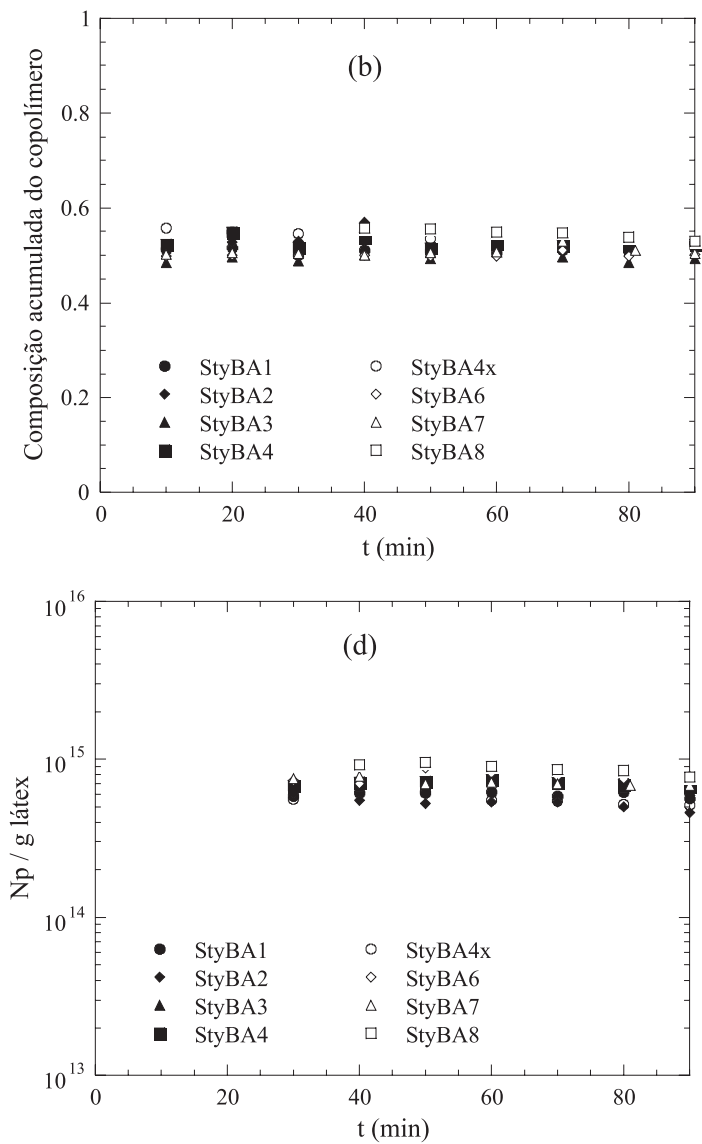

Figura 2. Evolução das reações semi-contínuas de copolimerização de estireno e acrilato de butila em emulsão antes da aplicação de diferentes estratégias para a redução do teor de monômero residual durante reações. a) Conversão global; b) Composição acumulada do copolímero (fração mássica de estireno); c) Diâmetro médio das partículas; d) Número de partículas por massa de látex. 
copolímero é constante (Figura $2 \mathrm{~b}$ ), apesar da diferença entre as razões de reatividade $\left(\mathrm{r}_{\mathrm{Sty}}=0,76 \mathrm{e}_{\mathrm{BA}}=0,19 \mathrm{a} 60^{\circ} \mathrm{C}\right)^{[9]}$. $\mathrm{Na}$ Figura $2 \mathrm{c}$ observa-se que o diâmetro médio final das partículas de polímero produzidas nestas reações é aproximadamente $90 \mathrm{~nm}$ e que não há uma variação significativa da evolução desta variável entre as reações. Na Figura 2 d notase que a partir dos 30 minutos de reação o número de partículas varia pouco ao longo das reações, indicando que com a formulação usada não ocorrem renucleações e/ou coalescência significativas.

As Figuras 3 a 6 comparam as evoluções dos teores de monômero residual, acrilato de butila e estireno, durante a reação base (StyBA1b) e durante reações nas quais foram adotadas diferentes estratégias visando a redução dos teores de monômeros. Como todas as reações seguem a mesma formulação (Tabela 1) até o final do período de alimentação, estas reações apresentam comportamento similar (Figura 2) e, portanto, nas Figuras 3 a 6 os resultados só serão apresentados a partir dos 100 minutos de reação, quando começaram a ser aplicadas as diferentes estratégias.

Na Figura 3 é apresentado o efeito do aumento da temperatura do meio reacional de $70{ }^{\circ} \mathrm{C}$ para $80{ }^{\circ} \mathrm{C} \mathrm{e} 90{ }^{\circ} \mathrm{C}$, respectivamente, nas reações StyBA2 e StyBA8 após o período de alimentação dos reagentes. $\mathrm{O}$ aumento de temperatura leva a
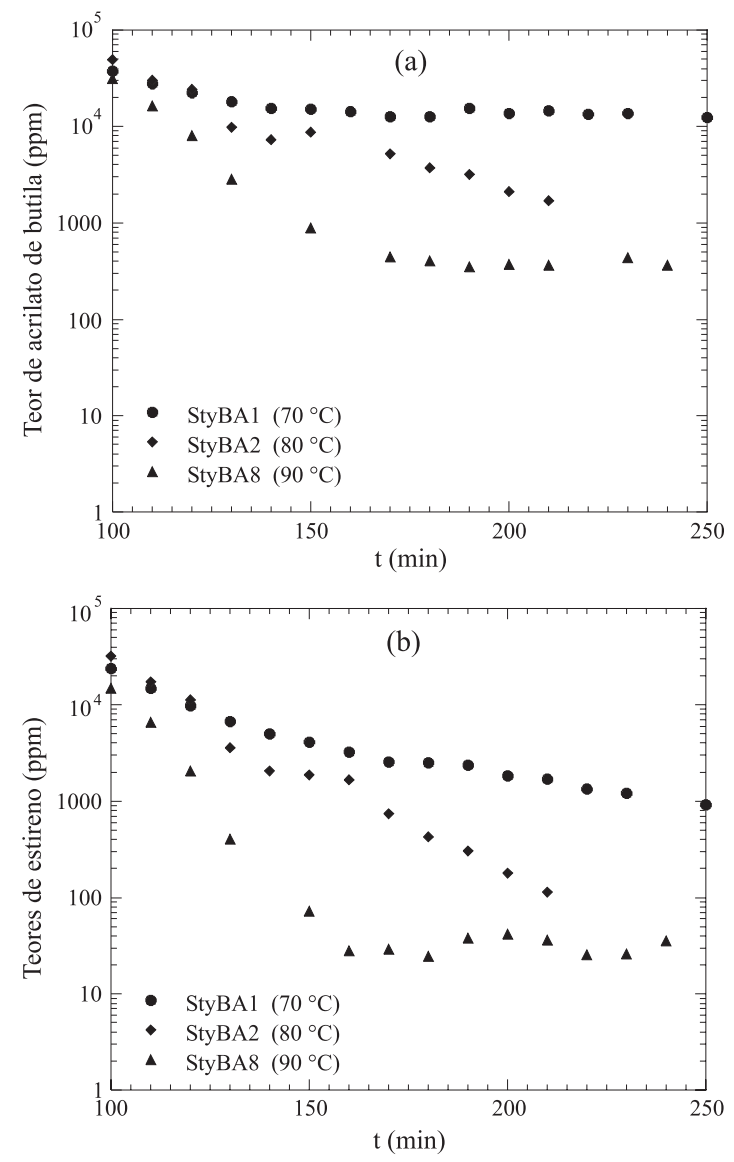

Figura 3. Comparação entre as diferentes estratégias usadas para a redução do teor de monômero residual durante reações semi-contínuas de copolimerização de estireno e acrilato de butila em emulsão. Efeito do aumento da temperatura na etapa final da reação. a) Acrilato de butila; b) Estireno. um aumento das taxas de propagação, de decomposição do iniciador e de difusão favorecendo a conversão do monômero.

$\mathrm{Na}$ Figura 4 observa-se que quando se combina o aumento da temperatura do meio reacional $\left(\right.$ de $70{ }^{\circ} \mathrm{C}$ para $\left.80^{\circ} \mathrm{C}\right)$ com a adição de iniciador (NaPS) ao final do período de alimentação dos reagentes, reação StyBA3, os teores de monômero residual alcançados são ainda mais baixos do que quando só se aplica o aumento da temperatura, reação StyBA2. Este resultado se deve ao aumento do número de radicais livres formados por decomposição térmica, já que o aumento da temperatura foi combinado com a adição de iniciador.

Quando são usadas temperaturas mais elevadas $\left(90^{\circ} \mathrm{C} \mathrm{em}\right.$ StyBA8 na Figura 3) a taxa de redução dos teores de monômero residual é maior durante os primeiros 60 minutos da póspolimerização do que quando é usada a estratégia que combina o aumento da temperatura do meio reacional de $70{ }^{\circ} \mathrm{C}$ para $80{ }^{\circ} \mathrm{C}$ com a adição de iniciador (NaPS), StyBA3 na Figura 4. Porém, é interessante observar que, enquanto na reação StyBA8 os teores de monômero residual permaneceram constantes a partir dos 60 minutos de pós-polimerização indicando a falta de radicais livres no meio reacional, na reação StyBA3 os teores de monômero residual decresceram continuamente durante todo o período de pós-polimerização e,
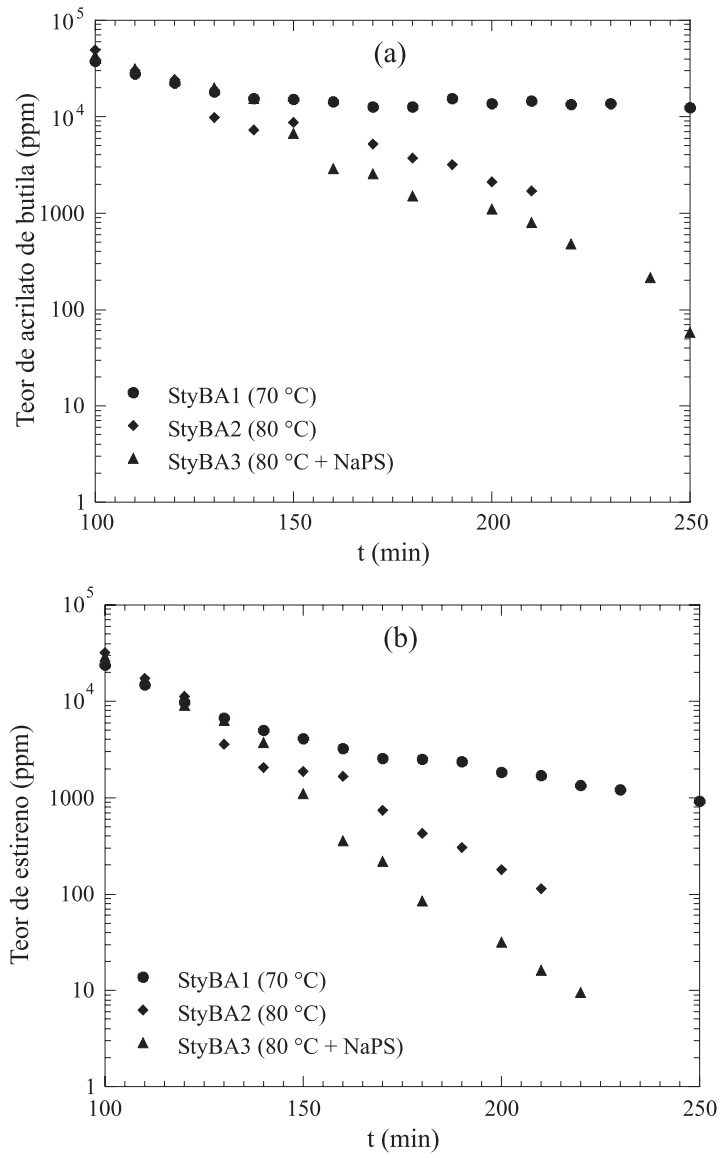

Figura 4. Comparação entre as diferentes estratégias usadas para a redução do teor de monômero residual durante reações semi-contínuas de copolimerização de estireno e acrilato de butila em emulsão. Efeito do aumento da temperatura e da adição de iniciador (NaPS) na etapa final da reação. a) Acrilato de butila; b) Estireno. 
consequentemente, os teores finais de monômero residual são mais baixos (Tabela 3 ).

Apesar de aumentar a taxa de formação de radicais, o emprego de um sistema de oxi-redução composto por persulfato de sódio e metabisulfito de sódio (agente redutor), alimentados separadamente, reações StyBA4 e StyBA4x na Figura 5, apresentou eficácia ligeiramente menor que o aumento da temperatura combinado com a adição de iniciador térmico, reação StyBa3 na Figura 4 e Tabela 3. Isto provavelmente se deve ao fato do sistema de oxi-redução só aumentar a taxa de formação de radicais e a estratégia combinada (aumento da temperatura e adição de iniciador térmico) resulta num aumento da taxa de formação de radicais e das constantes de propagação e de difusão.

Seria esperado que a adição de iniciador que forma radicais solúveis na fase polimérica (terc-butil-hidroperóxido - TBH), onde se encontram os monômeros, propiciasse uma redução mais eficiente dos teores de monômero residual na etapa final da polimerização. Entretanto, conforme pode ser observado na Figura 6 e na Tabela 3, não houve uma redução muito significativa dos teores de monômero residual. É possível que este resultado esteja relacionado com a forma de adição do TBH. Porém, por outro lado, Da Cunha e colaboradores ${ }^{[10]}$ verifica-
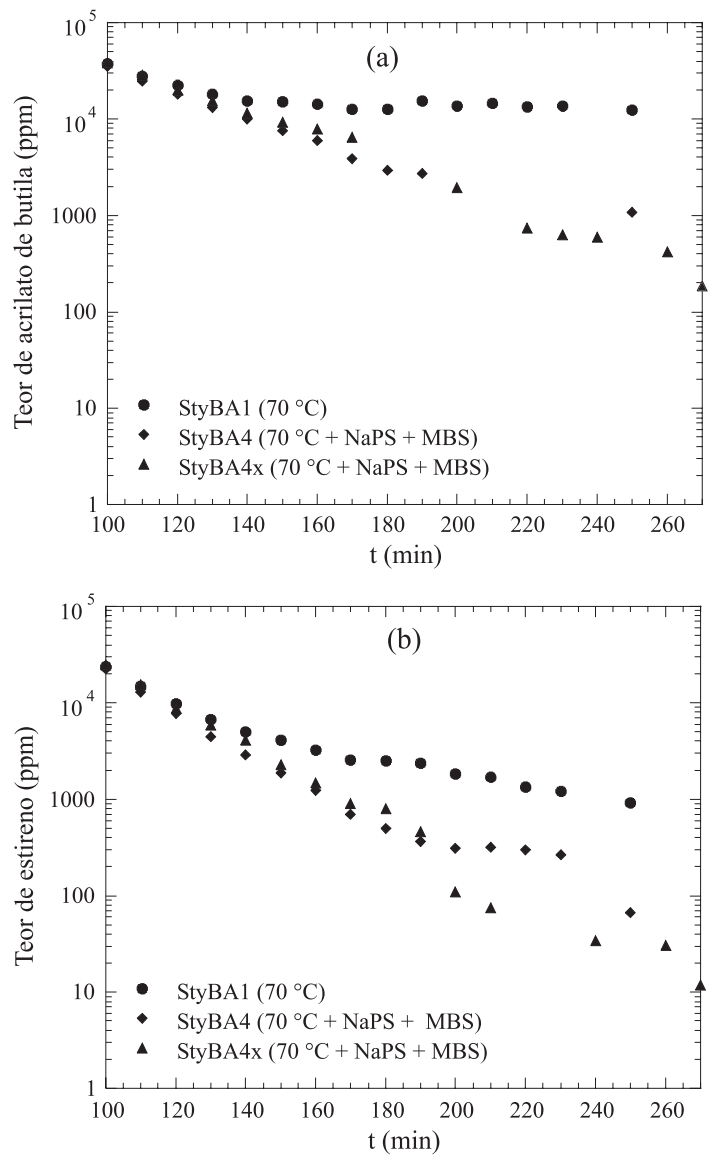

Figura 5. Comparação entre as diferentes estratégias usadas para a redução do teor de monômero residual durante reações semi-contínuas de copolimerização de estireno e acrilato de butila em emulsão. Efeito da adição de iniciador (NaPS + MBS) na etapa final da reação. a) Acrilato de butila; b) Estireno.
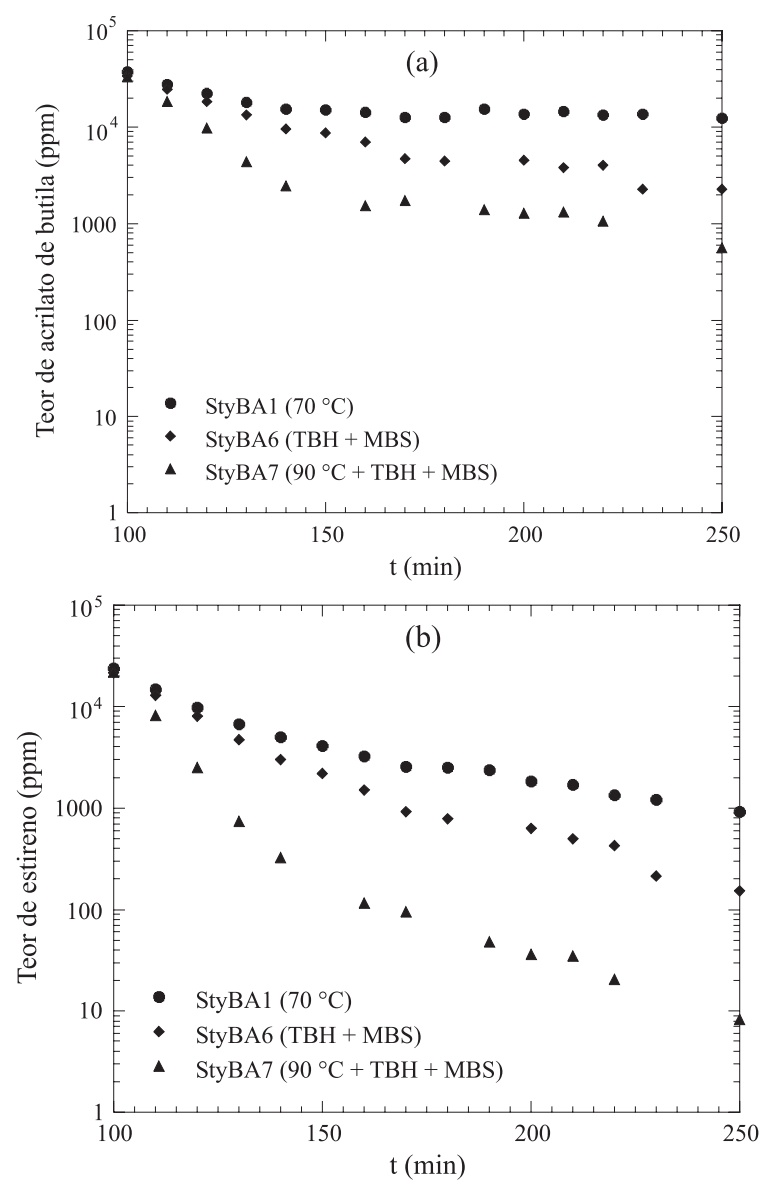

Figura 6. Comparação entre as diferentes estratégias usadas para a redução do teor de monômero residual durante reações semi-contínuas de copolimerização de estireno e acrilato de butila em emulsão. Efeito do aumento da temperatura e da adição de iniciador (TBH + MBS) na etapa final da reação. a) Acrilato de butila; b) Estireno.

ram que os radicais formados a partir de hidroperóxidos orgânicos além de reagirem com o monômero residual, também são consumidos em reações de cisão $\beta$ formando acetona e um radical ativo e em reações de abstração de hidrogênio de monômeros, polímero ou impurezas formando um t-butanol e um respectivo radical ativo. A formação destes compostos orgânicos voláteis (acetona e t-butanol), indesejáveis no produto final, certamente representa uma desvantagem do uso deste tipo de iniciador. Além disso, a acetona atua como inibidor da polimerização e, portanto, a sua formação pode reduzir a eficiência da redução dos teores de monômero residual.

Para finalizar, a Tabela 3 apresenta um resumo dos melhores resultados, teores finais de acrilato de butila e estireno obtidos com as diferentes estratégias testadas. Como o estireno é o monômero mais reativo nesta copolimerização $\left(r_{\text {Sty }}=0,76\right.$ e $r_{B A}=0,19$ a $\left.60{ }^{\circ} \mathrm{C}^{[9]}\right)$, os teores residuais finais de estireno são muito inferiores aos de acrilato de butila.

Os procedimentos adotados para reduzir os teores de monômero residual durante as reações de polimerização podem afetar a qualidade do polímero produzido, principalmente o peso molecular. Portanto, quando a aplicação do polímero exige um controle muito estrito desta propriedade deve-se avaliar o efeito destes procedimentos sobre o peso molecular e pro- 
Tabela 3. Teores de monômero finais após aplicação das estratégias para sua redução.

\begin{tabular}{cccc}
\hline Reação & Teor final de acrilato de butila $(\mathbf{p p m})$ & $\begin{array}{c}\text { Teor final de estireno } \\
(\mathbf{p p m})\end{array}$ & Estratégia \\
\hline StyBA1 & $\sim 10000$ & $\sim 1000$ & - \\
StyBA3 & $\sim 100$ & $\sim 10$ & $\mathrm{~T}=80^{\circ} \mathrm{C}+\mathrm{NaPS}$ \\
StyBA4x & $\sim 200$ & $\sim 10$ & $\mathrm{NaPS}+\mathrm{MBS}$ \\
StyBA7 & $\sim 500$ & $\sim 10$ & $\mathrm{~T}=90^{\circ} \mathrm{C}+\mathrm{TBH}+\mathrm{MBS}$ \\
StyBA8 & $\sim 300$ & $\sim 25$ & $\mathrm{~T}=90^{\circ} \mathrm{C}$ \\
\hline
\end{tabular}

T - temperatura; NaPS - persulfato de sódio; TBH - terc-butil-hidroperóxido; MBS - metabissulfito de sódio.

priedades relacionadas, como a fração de ramificações e o teor de gel. As estratégias adotadas neste trabalho, adição de diversos tipos de iniciadores e aumento da temperatura após o período de alimentação dos monômeros, podem afetar o peso molecular do polímero de diversas formas. Quando a conversão é baixa o aumento da temperatura e/ou o aumento da concentração de radicais levam a uma redução do peso molecular do polímero produzido. Entretanto, como neste trabalho as estratégias somente foram aplicadas após 90 e/ou 110 minutos de reação quando já foi alcançada uma conversão relativamente elevada, este efeito não é significativo. Por outro lado, em sistemas de polimerização nos quais as reações que dão origem a ramificações longas são significativas (caso do acrilato de butila), a temperatura e a concentração de radicais afetam (aumentam) as taxas das reações de transferência de cadeia ao polímero e das reações com duplas ligações terminais e, portanto, aumentam a frequência de formação de ramificações, o peso molecular e, eventualmente, o teor de gel. Para algumas aplicações estes efeitos podem ser benéficos, para outras, nas quais são desejados polímeros com pesos moleculares baixos e/ou baixas frequências de ramificação e/ou baixos teores de gel, este efeito pode ser evitado através do uso de agentes de transferência de cadeia e/ou do aumento da concentração de iniciador e temperatura na etapa inicial da reação quando a conversão é baixa, procedimento que poderia ter como vantagem adicional a redução do tempo de reação. Portanto, como prosseguimento deste trabalho pretende-se estudar o efeito das estratégias para redução dos teores de monômero residual sobre a qualidade do polímero, peso molecular, teor de gel, amarelamento, estabilidade do látex, teor de coágulos, formação de outros produtos orgânicos voláteis ${ }^{[10]}$, e, quando necessário, desenvolver medidas corretivas.

\section{Conclusões}

Neste trabalho foram comparadas diversas estratégias para a redução dos teores de monômero residual em reações semicontínuas de copolimerização de estireno e acrilato de butila em emulsão. Os resultados mostram a superioridade das técnicas combinadas. Verificou-se que combinando o aumento da temperatura ao final da reação para $80{ }^{\circ} \mathrm{C}$ com a alimentação de iniciador térmico (persulfato de sódio) é possível atingir uma redução de $99 \%$ dos teores de monômero residual, tanto para estireno, como para acrilato de butila, que é o monômero menos reativo desta copolimerização.

\section{Agradecimentos}

À Fapesp - Fundação de Amparo à Pesquisa do Estado de São Paulo e ao CNPq pelo apoio financeiro e pela bolsa PROFIX - CNPq para Pedro H. H. Araújo. E à Raisio Chemicals pelo fornecimento de monômeros.

\section{Referências Bibliográficas}

1. Englund, S. M. - Chem. Eng. Prog., August, p.55, (1981).

2. Araújo, P. H. H.; Sayer, C.; Poço, J. G. R. \& Giudici, R. Polym. Eng. Sci., 42, p.1442, (2002).

3. Anderson, L. L. \& Brouwer, W. M. - Coating Tech., 68, p.75, (1996).

4. Dobbelaar, J.; Hubinger, W.; Keller, P. \& Stanger, B. U.S. Patent 6,096,858, (2000).

5. Sempio, C.; Saija, L. M.; Becchi, D. \& Montessoro, E. U.S. Patent 5,721,310, (1998).

6. Kolb, B. - J. Chrom. A, 842, p.163, (1999).

7. Strassnig, S. \& Lankmayr, E.P. - J. Chrom. A, 849, p.629, (1999).

8. Leiza, J. R., de la Cal, J. C., Montes, M. \& Asua, J. M. Process Control and Quality, 4, p.197, (1993).

9. Encyclopedia of Polymer Science and Technology, vol. 4, John Wiley \& Sons, (1966).

10. Da Cunha, L.; Ilundain, P.; Salazar, R.; Alvarez, D.; Barandiaran, M J. \& Asua, J. M. - Polymer, 42, p.391, (2001).

Recebido: 04/09/03

Aprovado: 17/12/03 